\title{
Improvement spectrometric gamma measurements on shale cores with the use of the BGO scintillation detector
}

\begin{abstract}
Spectrometric gamma measurements carried out on rock cores of shale formations belong to standard petrophysical analyses. The paper presents the work performed to improve the possibilities of recording natural gamma radiation on cores. The performed work was related to the modification of a gamma logger device, creating calibration standards and developing new computer software to calculate real element concentrations from the measured spectra. Results obtained from various methods have been compared in order to choose a methodology which is as good as possible. The final conclusions were based on the comparison of gamma measurements on the core with measurement results from a logging SGR logging probe and with the results of laboratory measurements.
\end{abstract}

Key words: gamma spectrometry, BGO crystal, clay content, gamma logging, shale rocks.

\section{Udoskonalanie spektrometrycznych pomiarów gamma na rdzeniach skał łupkowych z wykorzystaniem detektora scyntylacyjnego BGO}

\begin{abstract}
Spektrometryczne pomiary gamma prowadzone na rdzeniach wiertniczych formacji skał łupkowych należą do standardowych analiz geofizycznych. W niniejszej publikacji przedstawione zostały prace wykonane w celu poprawy możliwości rejestracji naturalnego promieniowania gamma na rdzeniach. Prowadzone prace dotyczyły modyfikacji urządzenia gamma logger, stworzenia wzorców kalibracyjnych oraz napisania nowego programu komputerowego do przeliczania widm spektrometrycznych na rzeczywiste koncentracje pierwiastków. Wyniki otrzymywane z różnych metod zostały porównane między sobą, w celu wyboru jak najlepszej metodyki. Końcowe wnioski oparte zostały o zestawienie pomiarów gamma na rdzeniu wraz z wynikami pomiarów z sondy geofizycznej SGR i wynikami pomiarów laboratoryjnych.
\end{abstract}

Słowa kluczowe: spektrometria gamma, kryształ BGO, zailenie, profilowanie gamma, skały łupkowe.

\section{Introduction}

Spectrometric gamma logging is a standard measurement performed during driving a logging string into a borehole. Gamma measurements are used mainly to estimate the amount of clays during comprehensive well log interpretation, determining stratigraphic boundaries and borehole correlations [4]. They also allow depth matching of the core interval to borehole measurements, which is particularly important at the correlation of laboratory studies with petrophysical measurements. In addition, they are used to assess the type of clay minerals based on the thorium to potassium content ratio, the estimated amount of organic matter based on the authigenic uranium content [8], the determination of fractured zones, and the determination of the depositional environment (uranium/thorium ratio).

The first probes for measurements of natural rock radiation were equipped with gas Geiger-Müller detectors, recording the number of counts originating from the emitted total energy. The tool record was given in units of counts frequency (counts per minute $[\mathrm{cpm}]$ or counts per second $[\mathrm{cps}]$ ), which made comparison of logging results impossible. Measuring sets, characterized by different parameters of crystal and of recording unit, gave different count values. Gas detectors 
were replaced by scintillation detectors, which were more effective and enabled the separation of energies originating from different elements, and were built mainly based on a sodium iodide (NaI) crystal [6]. The result of calculations performed on an energy spectrum registered using such a counter consists of potassium [\%], uranium [ppm], thorium [ppm] and "total” (the summary value of radiation). Each of the specified elements emits a characteristic energy appearing in a spectrum as a peak; the energy for potassium is $1.46 \mathrm{MeV}$, for uranium $-1.76 \mathrm{MeV}$, for thorium $-2.62 \mathrm{MeV}$. Summary results of measurements using gamma tools are now scaled in API (American Petroleum Institute) units [11]. This is a unit introduced in 1960 aimed at the standardisation of gamma tool readings. Because of all sondes are calibrated in the API unit, despite various detector types, results are comparable. Gamma logging carried out in Poland before 1990 require calibration of the $\log [3]$.

Measurements on cores are carried out using various instrument types, differing in detecting unit parameters, calculation methods and dimensions. Handheld spectrometers are the smallest ones. Their small size is an advantage, as well as providing the possibility to make measurements on outcrops [5]. An additional detector shield and a supporting stand are required to measure cores using this instrument. The lack of possibility to obtain real element concentrations is their disadvantage. Spectrometers dedicated for core measurements have an appropriate shape enabling setting them directly on a cylinder's surface, and a mechanism allowing free movement along the profile. Their casings are made of a thicker lead layer to attenuate the background signal [11]. Spectrometers are equipped with external computers enabling the control and calibration the device. Mobile devices equipped with an automatic system enabling moving the detector above the rock core, or with a set of many detectors working with each other are more and more often used. The application of many analysers enables measuring a few points at the same time. Unfortunately, detectors are the most expensive part of the instrument, and therefore their number is usually limited to the minimum [13].

In the case of borehole measurements the high ratio of radiation emitted by the rock strata to the value of the measurement background has a favourable influence on accuracy and precision. Even in the case of strata with low contents of radioactive elements the record is readable. However, in borehole measurements the record's accuracy may be affected by many factors, which should be considered during the interpretation. The influences of the drilling mud, of vugs or fractures, washouts or temperature belong to the most frequently occurring ones. In the case of drilling mud it is important to know their chemical composition and to take its influence on the intended values into account. Vugs or fractures and washouts cause a significant local drop in values. Temperature is the factor affecting detector stability, as its sudden change may disturb the measured values [10].

Measurements carried out on cores are devoid of the influence of disturbing factors existing in boreholes. Unfortunately, they are burdened with high values of measurement background [9], which can frequently have values higher than the signal emitted by the core. This results in negative values on the log. The application of additional screens is the only possibility to reduce the background impact, which in the case of very low contents of radioactive elements and the impact of statistic fluctuations does not allow obtaining a correct result.

\section{Methods}

Increasingly high requirements set for the measurement results' accuracy motivate the improvement of methods, the increasing of the equipment's efficiency, and the search for new instrument solutions. Devices usually equipped with $\mathrm{NaI}(\mathrm{Tl})$ (thallium activated sodium iodide) and BGO $\left(\mathrm{Bi}_{4} \mathrm{Ge}_{3} \mathrm{O}_{12}\right.$ - bismuth germanate) are now used in field tests. It is also possible to use HPGe (High Purity Germanium) detectors built based on a semiconductor crystal with the highest available resolution. As they can be applied only at low temperatures, they are used mainly in laboratories. New minimised cooling systems allow the application of such devices in the field.

Unfortunately, the high price of semiconductor detectors and their low resistance to external conditions have contributed to their limited use. Moreover, they have a low efficiency, which translates into long measurement times, undesirable in the case of field work.

The studies described in this paper comprised measurements performed by devices equipped with $\mathrm{NaI}(\mathrm{Tl})$ and $\mathrm{BGO}$ crystals. A device equipped with a $\mathrm{NaI}(\mathrm{Tl})$ crystal, according to the manufacturer, was adapted for qualitative and quantitative measurements of radioactive elements - potassium, uranium and thorium - contents, and for the measurement of total gamma radiation emitted by the core. The software controlling this device for the 'spectral' mode enables a measurement, which takes 5 minutes. The described spectrometer is built based on a crystal, of dimensions $2 " \times 2 "$. The measuring set is equipped with a kit of calibration standards.

An automated device (Fig. 1) was the second tested instrument, equipped with a BGO scintillation crystal $2 " \times 2 "$ 


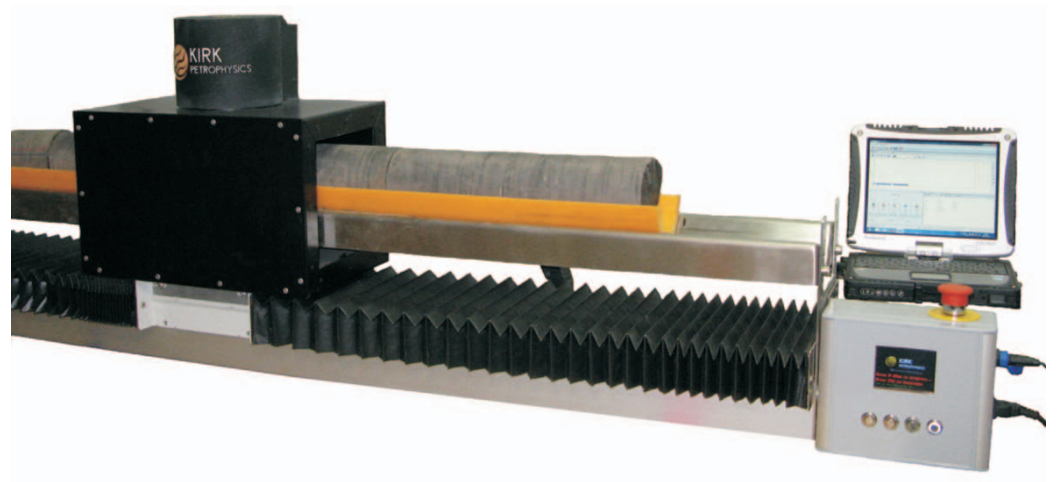

Fig. 1. Gamma Logger device (BGO)

featuring a high efficiency (around 10\% higher than in the case of NaI) [12].

To enable measurements of actual concentrations of radioactive elements using the BGO device, calibration standards were made for this instrument. To this end cooperation with the company GEORADIS s.r.o. was undertaken, and two sets of standards, $8 \mathrm{~cm}$ and $10 \mathrm{~cm}$ in diameter (Fig. 2) were created, comprising potassium, uranium, thorium standards and an inactive aluminium standard. New standards were made in such a way that their shape would match the core shape. Radioactive elements were uniformly distributed throughout the entire standard volume. Table 1 gives their concentrations. In the case of measuring cores

Table 1. Values of natural radioactive element concentrations in the produced standards, 8 and $10 \mathrm{~cm}$ in diameter

\begin{tabular}{|l|c|c|c|c|c|c|}
\cline { 2 - 7 } \multicolumn{1}{c|}{} & \multicolumn{6}{c|}{ Element concentrations } \\
\cline { 2 - 7 } \multicolumn{1}{c|}{} & \multicolumn{4}{c|}{$8 \mathrm{~cm}$ diameter } & \multicolumn{3}{c|}{$10 \mathrm{~cm}$ diameter } \\
\hline Standard & $\mathrm{K}[\%]$ & $\mathrm{U}[\mathrm{ppm}]$ & $\mathrm{Th}[\mathrm{ppm}]$ & $\mathrm{K}[\%]$ & $\mathrm{U}[\mathrm{ppm}]$ & $\mathrm{Th}[\mathrm{ppm}]$ \\
\hline Potassium & 27 & 1 & 6 & 24 & 1 & 8 \\
\hline Uranium & 0 & 152 & 12 & 1 & 167 & 40 \\
\hline Thorium & 0 & 4 & 250 & 1 & 3 & 268 \\
\hline Inactive & 0 & 0 & 0 & 0 & 0 & 0 \\
\hline
\end{tabular}

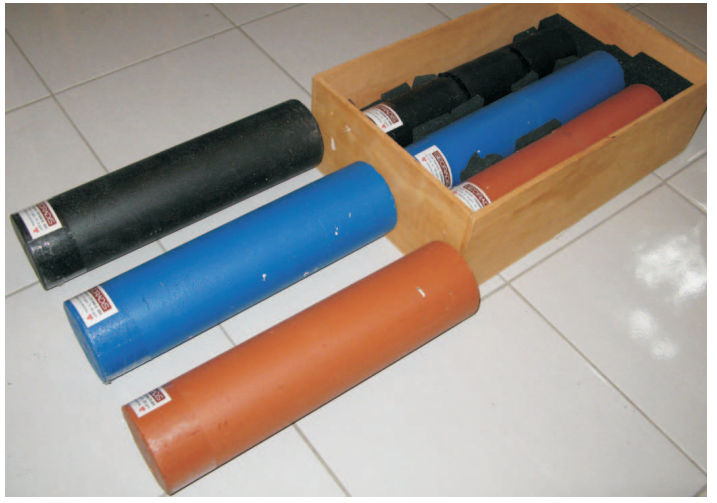

Fig. 2. Sets of active calibration standards of other diameters it is possible to convert the results using a coefficient, determined based on a larger number of standards, measured in a radiometric laboratory.

The gamma logger (BGO) does not have possibilities of calibrating the measurements. Spectra from non-calibrated measurements are exported to an external computer using the RSAnalyst software. To enable calibration on cores, based on standards, an external company specialised in the construction of radiometric detecting devices and in software development was hired. The first measurement tests were carried out on the LabCenter computer software, which can control a detector by connecting the device to the external computer. The LabCenter allows creating and saving a measurement configuration. An appropriate number and width of ROI-s (regions of interest) should be set during its creation; these are values of windows which are to be used in the spectrum computation (a possibility to set from 1 to 9 windows). The calibration process requires, a series of standard measurements which must be performed on the site of the carried out work. The software advantage consists in the possibility of saving calibration spectra and of using them again, which allows time saving. However, the best practice is to calibrate the device before each measurement series, due to the possibility of significant changes in the background value, which may affect the results. The lack of possibilities for performing measurement series is a drawback of the LabCenter software, which in the case of continuous core logging creates a lot of difficulties.

To verify the gamma logger results, measurements were carried out using a laboratory MAZAR spectrometer. The MAZAR is adapted to measure crushed samples, in the amount of approx. $150 \mathrm{~g}$, in a container. The measuring chamber of the instrument is shielded from all sides by an approx. $5 \mathrm{~cm}$-thick layer of lead. The instrument is equipped with a scintillation detector with a two-inch $\mathrm{NaI}$ crystal. The time of measurement by the instrument for one sample is around 6 hours.

The result of the measurement by a petrophysical probe, broken down into individual radioactive elements: $\mathrm{K}, \mathrm{U}, \mathrm{Th}$ (SGR - spectral gamma ray), is an additional reference point presented in the paper. 


\section{Results}

Data originating from the gamma logger (NaI and BGO), MAZAR and results of the sonde were used to carry out analyses.

In the first stage the test measurements on two instruments available at the Oil and Gas Institute - National Research Institute, with $\mathrm{NaI}$ and BGO crystals, were performed. Table 2 presents the results of those comparisons. Measurement results from the NaI gamma logger were taken from the Skupio [11]. Measurements using a new instrument with a BGO crystal were made on the same samples, without the use of calibration standards. This study was aimed only at checking the measurement error values.

The table specifies results from two instruments, with different detectors, related to four sections of cores. They comprise results of five measurements, based on which the mean, the standard deviation and the measurement error were calculated ('STAT' column). The error was distinguished to make its comparison between two instruments. Mean values are not comparable due to missing calibration standards for the BGO instrument. It is possible to notice that results obtained from measurements by the $\mathrm{BGO}$ gamma spectrometer feature an improved precision, despite the fact that the performance of measurements in the time that was 5 times shorter.

Based on the above information, the decision was made to use only the instrument equipped with the BGO crystal for further studies.

The first test measurements using the new gamma logger (BGO) instrument were carried out on short core sections in the laboratory. Random samples from various depths were taken for measurements; the core sections were approx. $30 \div 40 \mathrm{~cm}$ long. The time of core analysis in the portable gamma logger (BGO) instrument was set as 5 minutes. The LabCenter computer software and the calibration standards were used for analytical purposes. After the completion of measurements on the core, the material was crushed and quartered to homogenise the sample, and tested on stationary MAZAR spectrometer. The analysis of the crushed material in laboratory conditions took around 6 hours. Studies were performed on samples taken from two boreholes, $\mathrm{X}-1$ and $\mathrm{Y}-1$.

Table 2. Comparison of results: NaI gamma logger (measurement time of 5 minutes) and BGO (measurement time of 1 minute)

\begin{tabular}{|c|c|c|c|c|c|c|c|c|}
\hline & \multicolumn{8}{|c|}{ Gamma Logger (NaI) } \\
\hline & $\begin{array}{c}\mathrm{K} \\
{[\%]}\end{array}$ & STAT & $\begin{array}{c}\mathrm{U} \\
{[\mathrm{ppm}]}\end{array}$ & STAT & $\begin{array}{c}\mathrm{Th} \\
{[\mathrm{ppm}]}\end{array}$ & STAT & $\begin{array}{c}\text { TOTAL } \\
\text { [API] }\end{array}$ & STAT \\
\hline \multirow{5}{*}{$\mathrm{C} 1$} & 1.68 & & 16.76 & & 16.10 & & 154.38 & \\
\hline & 2.56 & 2.32 & 8.56 & 11.57 & 15.18 & 14.27 & 152.95 & 152.16 \\
\hline & 2.29 & 0.39 & 10.63 & 3.07 & 18.39 & 4.06 & 147.66 & 3.05 \\
\hline & 2.67 & 16.65 & 10.75 & 26.53 & 7.57 & 28.48 & 150.64 & 2.01 \\
\hline & 2.40 & & 11.17 & & 14.11 & & 155.18 & \\
\hline \multirow{5}{*}{$\mathrm{C} 2$} & 2.47 & & 13.67 & & 12.10 & & 177.55 & \\
\hline & 2.36 & 1.97 & 12.94 & 13.72 & 18.61 & 15.00 & 170.04 & 170.21 \\
\hline & 1.53 & 0.52 & 18.36 & 3.85 & 12.65 & 4.75 & 168.37 & 4.29 \\
\hline & 1.50 & 26.55 & 15.68 & 28.03 & 21.38 & 31.67 & 168.54 & 2.52 \\
\hline & 3.32 & & 7.96 & & 10.25 & & 166.53 & \\
\hline \multirow{5}{*}{$\mathrm{C} 3$} & 2.43 & & 8.43 & & 16.97 & & 155.45 & \\
\hline & 2.64 & 2.57 & 9.90 & 8.72 & 15.90 & 18.77 & 160.89 & 156.35 \\
\hline & 3.02 & 0.42 & 6.65 & 6.55 & 18.66 & 9.07 & 159.34 & 5.13 \\
\hline & 1.93 & 16.42 & 18.39 & 75.06 & 8.79 & 48.33 & 158.18 & 3.28 \\
\hline & 2.85 & & 0.23 & & 33.54 & & 147.88 & \\
\hline \multirow{5}{*}{$\mathrm{C} 4$} & 2.02 & & 8.57 & & 8.44 & & 20.78 & \\
\hline & 2.09 & 1.91 & 5.22 & 6.52 & 13.13 & 13.13 & 16.42 & 18.75 \\
\hline & 2.19 & 0.34 & 4.55 & 1.62 & 14.19 & 4.86 & 20.13 & 2.01 \\
\hline & 1.92 & 17.74 & 7.03 & 24.88 & 9.25 & 37.03 & 19.63 & 10.70 \\
\hline & 1.33 & & 7.21 & & 20.64 & & 16.78 & \\
\hline
\end{tabular}

\begin{tabular}{|c|c|r|r|r|r|r|r|}
\hline \multicolumn{7}{|c|}{ Gamma Logger (BGO) measure time: 1 min } \\
\hline $\begin{array}{c}\text { K } \\
{[\%]}\end{array}$ & STAT & $\begin{array}{c}\text { U } \\
{[\mathrm{ppm}]}\end{array}$ & STAT & $\begin{array}{c}\text { Th } \\
{[\mathrm{ppm}]}\end{array}$ & STAT & $\begin{array}{c}\text { TOTAL } \\
{[\mathrm{ppm}]}\end{array}$ & STAT \\
\hline 2.2 & & 13.1 & & 22.60 & & 134.1 & \\
\hline 2.5 & $\mathbf{2 . 4 8}$ & 13.0 & $\mathbf{1 2 . 6 6}$ & 21.50 & $\mathbf{2 1 . 7 8}$ & 134.4 & $\mathbf{1 2 9 . 8 8}$ \\
\hline 2.2 & 0.28 & 13.2 & 0.88 & 24.40 & 2.99 & 125.0 & 4.73 \\
\hline 2.8 & 11.19 & 11.1 & 6.94 & 16.80 & 13.72 & 124.8 & 3.64 \\
\hline 2.7 & & 12.9 & & 23.60 & & 131.1 & \\
\hline 3.1 & & 12.2 & & 25.70 & & 146.5 & \\
\hline 2.7 & $\mathbf{2 . 6 2}$ & 13.8 & $\mathbf{1 4 . 7 2}$ & 21.10 & $\mathbf{2 2 . 9 4}$ & 143.8 & $\mathbf{1 4 2 . 9 4}$ \\
\hline 2.5 & 0.33 & 18.1 & 2.16 & 22.30 & 1.78 & 144.2 & 2.85 \\
\hline 2.2 & 12.49 & 15.0 & 14.71 & 22.00 & 7.78 & 139.3 & 1.99 \\
\hline 2.6 & & 14.5 & & 23.60 & & 140.9 & \\
\hline 3.9 & & 19.0 & & 29.10 & & 176.4 & \\
\hline 3.1 & $\mathbf{3 . 2 8}$ & 19.2 & $\mathbf{1 9 . 4 6}$ & 22.90 & $\mathbf{2 6 . 2 4}$ & 160.5 & 168.58 \\
\hline 2.9 & 0.38 & 18.5 & 0.84 & 27.00 & 2.42 & 162.3 & 6.97 \\
\hline 3.3 & 11.49 & 20.0 & 4.29 & 27.40 & 9.20 & 170.0 & 4.13 \\
\hline 3.2 & & 20.6 & & 24.80 & & 173.7 & \\
\hline 2.1 & & 10.4 & & 1.08 & & 109.5 & \\
\hline 2.5 & $\mathbf{2 . 7 6}$ & 7.8 & $\mathbf{9 . 1 0}$ & 17.10 & $\mathbf{2 1 . 2 8}$ & 109.9 & $\mathbf{1 1 0 . 9 2}$ \\
\hline 3.3 & 0.50 & 7.7 & 2.53 & 23.90 & 4.35 & 113.9 & 2.36 \\
\hline 2.7 & 18.04 & 12.9 & 27.77 & 19.90 & 20.44 & 108.4 & 2.12 \\
\hline 3.2 & & 6.7 & & 27.50 & & 112.9 & \\
\hline & & & & & & & \\
\hline 3.2 & & & & & \\
\hline
\end{tabular}

STAT

mean

standard deviation

measurement error 
Core: $\mathbf{X}-\mathbf{1}$
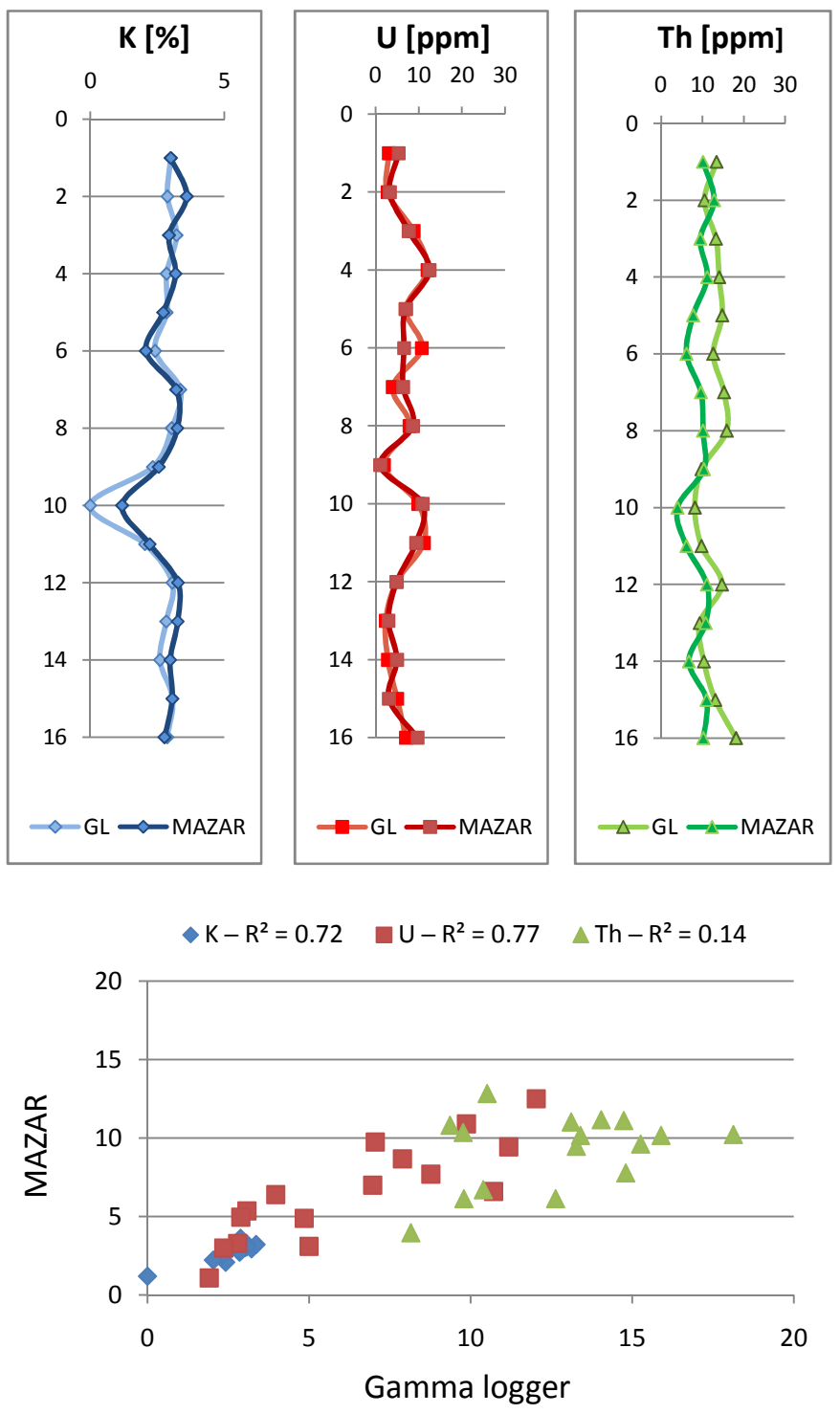

Fig. 3. Measurement results for cores X-1 and Y-1: GL - gamma logger (BGO), MAZAR - the laboratory spectrometer

The results of measurements are presented in graphs in the form of sections of spectrometric gamma logging, and in correlation graphs, giving the value of the determination coefficient for individual elements' relationships (Fig. 3).

The results presented in Figure 3 illustrate the correctness of spectrometer operation, the correctness of calibration standards execution, and of the computational method applied in the LabCenter software. The analysis of graphs allows stating that measurements on the Y-1 core have a higher determination coefficient. Measurement series were performed at a certain time interval; the X-1 core was measured as the first. The slightly worse quality of results might have been affected by a number of factors, which at the beginning of instrument use were not fully understood. Examples may comprise a too short instrument warming up time, an unstable temperature, or an error at the calibration of any standard. Measurements carried out on the Y-1 core had a high value of determination

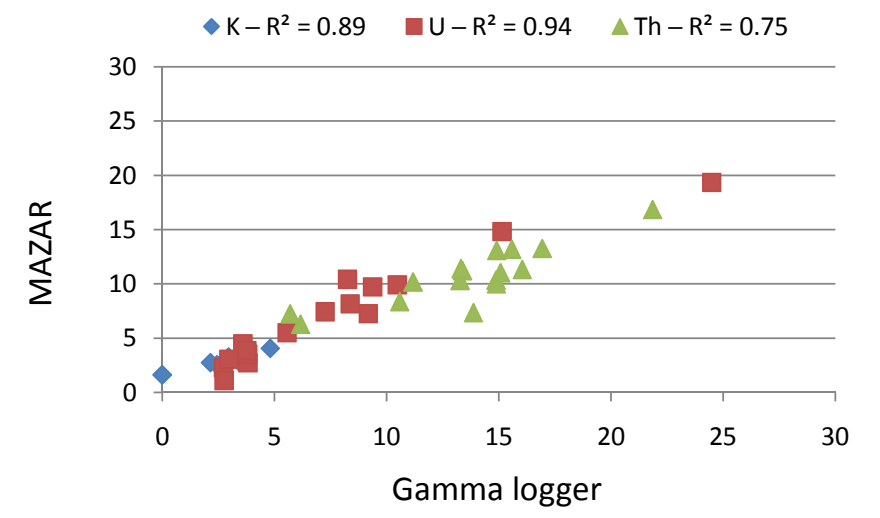

Core: Y-1

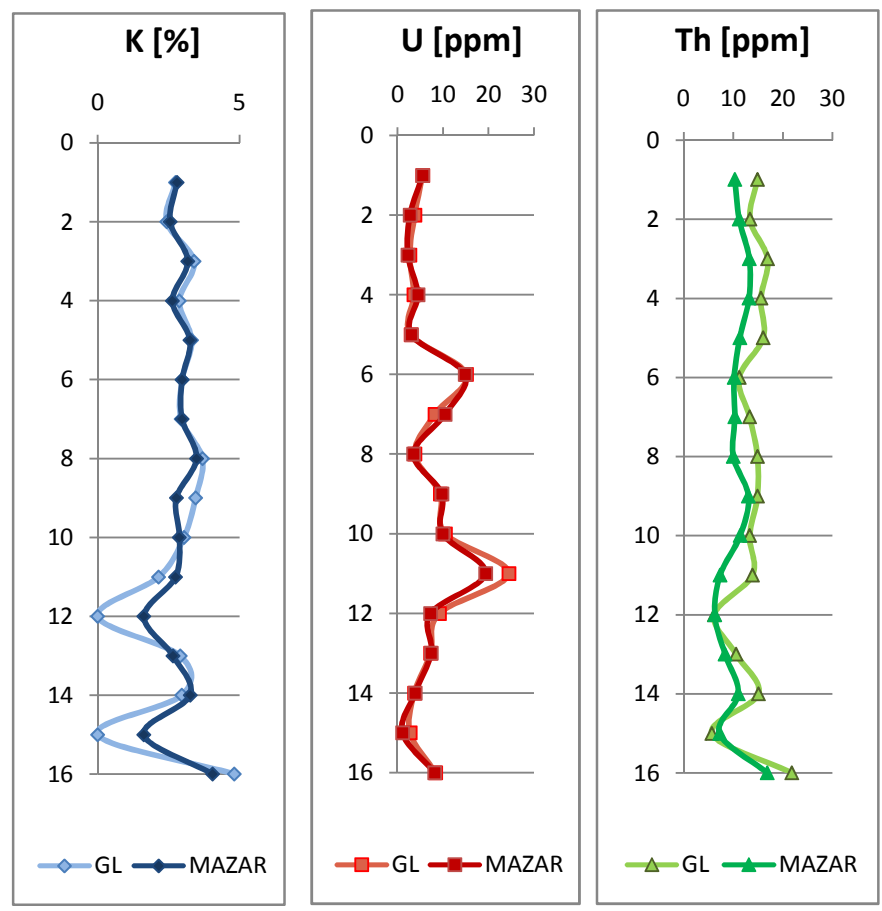

coefficient for all investigated elements, which confirmed the correctness of the measurement method operation.

The work on improving the measurement method included the development of a new computational module, working with the 'RSAnalyst' software, allowing the conversion of the measured spectra into real concentrations of radioactive elements. Contrary to the LabCenter software, the measurement is recorded in the form of a non-calibrated *spc. file, and then calculated referring to standards' spectra. The new computer software, operating independently of the device, was developed by the producer of software used so far, and allowed the calculation of the entire series of measured spectra.

During the next studies there was no possibility to do measurements on the cores in the laboratory. Measurements performed under the project comprised cores from T-1 and M-1 boreholes, in the core storage, and then samples were taken for laboratory tests. 
The field work requires shortening the analysis time to the minimum, parallel to achieving as accurate as possible results. The analysed cores from T-1 and M-1 boreholes were measured along their entire length, with a predetermined measuring step of $0.1 \mathrm{~m}$, at an exposure time of 1 minute (considering the detector's dead time and the spectrum recording, the analysis took 78 seconds), which in the case of shale rocks with high contents of radioactive elements ensured a sufficient quality of signal.

Individual depth points, corresponding to samples taken for laboratory measurements, were selected from the measurement performed on the entire core. In the case of results correlation certain changes of the measurement environment, affecting its quality, should be considered. The measurement on the core is continuous, and in the case of the boundary between a highly radioactive and a low radioactive layers there is an influence of individual layer on each other, causing averaging of the values. Samples for laboratory measurements may be taken from one of layer, which would substantially change the end result. Fig. 4 presents values calculated using the new software, marked with colours, and the black log shows the reference results from laboratory measurements.

Graphs (Fig. 4) show a slightly worse fit than in the case of measurements performed in the lab, on short sections of core X-1, Y-1 (Fig. 3). The factors described before may be the reason.

The GL_calc results presented in the graphs refer to measurements by means of the gamma logger (BGO), on the core, using the new module for spectra calculation. The computational software was deprived of the detection limit, because of which higher possibilities of log fluctuation changes in low ranges existed (possibility of measuring cores of reduced activity of radioactive elements). In the case of measuring very low radioactive cores, the rock material itself may be less active than the surrounding background. That in turn will generate negative values on the log, which show
Borehole: T-1
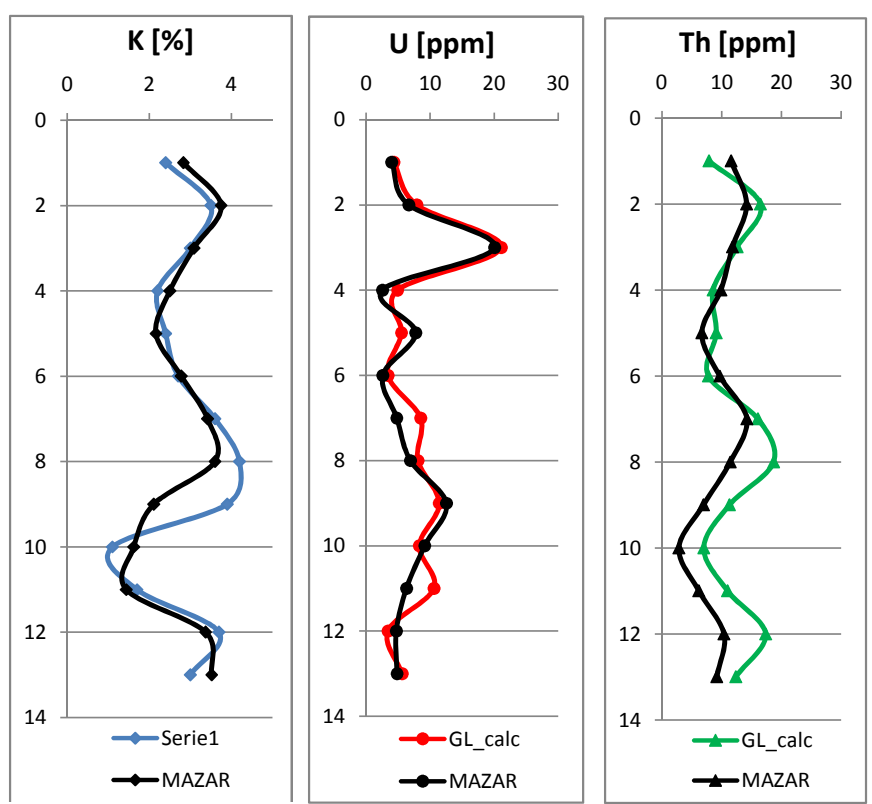

$-\mathrm{K}-\mathrm{R}^{2}=0.55 \quad \mathrm{U}-\mathrm{R}^{2}=0.84$

$T h-R^{2}=0.37$

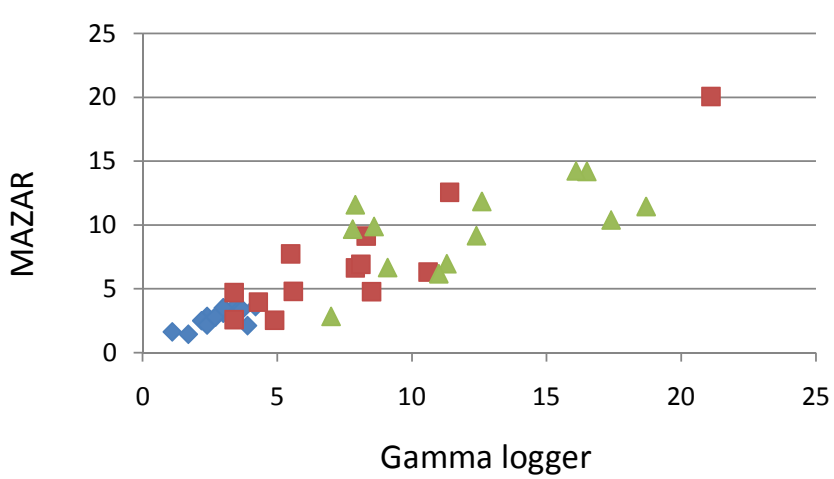

Borehole: M-1

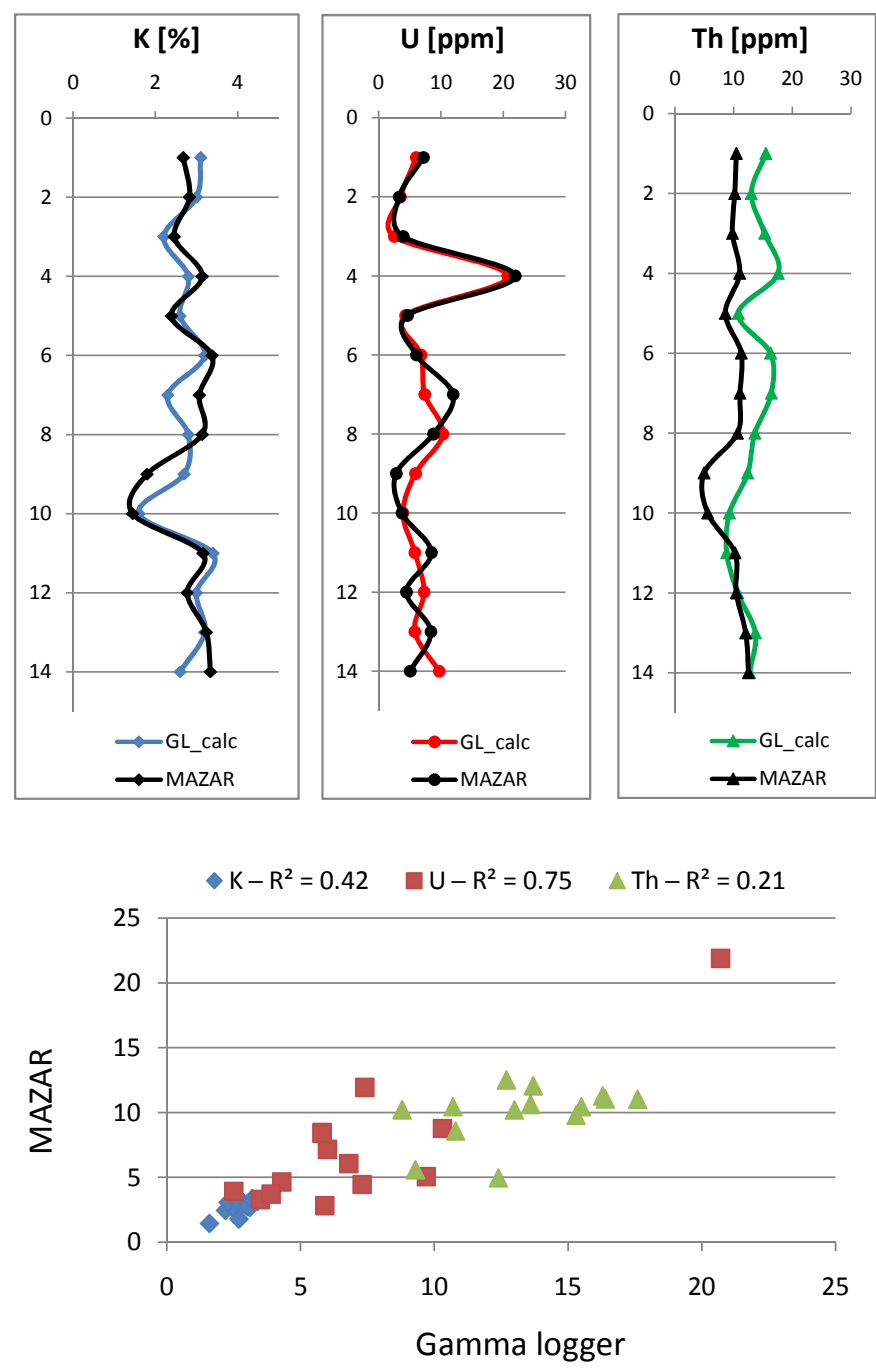

Fig. 4. Comparison of logs built based on measurements performed on the core (measurement time: 1 minute) with the reference log, obtained based on laboratory measurements on the MAZAR spectrometer (measurement time: 6 hours) 
diversification of layers, but do not allow using them in the quantitative interpretation. The results of laboratory and field measurements will be presented later on, which prove the correctness of the operation of the instrument and computer software in calculating the spectra. The next tests consisted in performing measurements for approx. $110 \mathrm{~m}$ of core from the T-1 borehole. Then 1100 measured spectra were recalculated. A profile of gamma logger data, together with the borehole tool data and reference points (measurements on the MAZAR), was created based on the results. Depth matching was applied in the profile: the log depth was matched to the drilling depth. The final results are presented for a selected core section, featuring a lithological variability: true depths have been changed (Fig. 5).

The use of the new computer software to calculate the real concentrations of radioactive elements allowed an accurate

A.
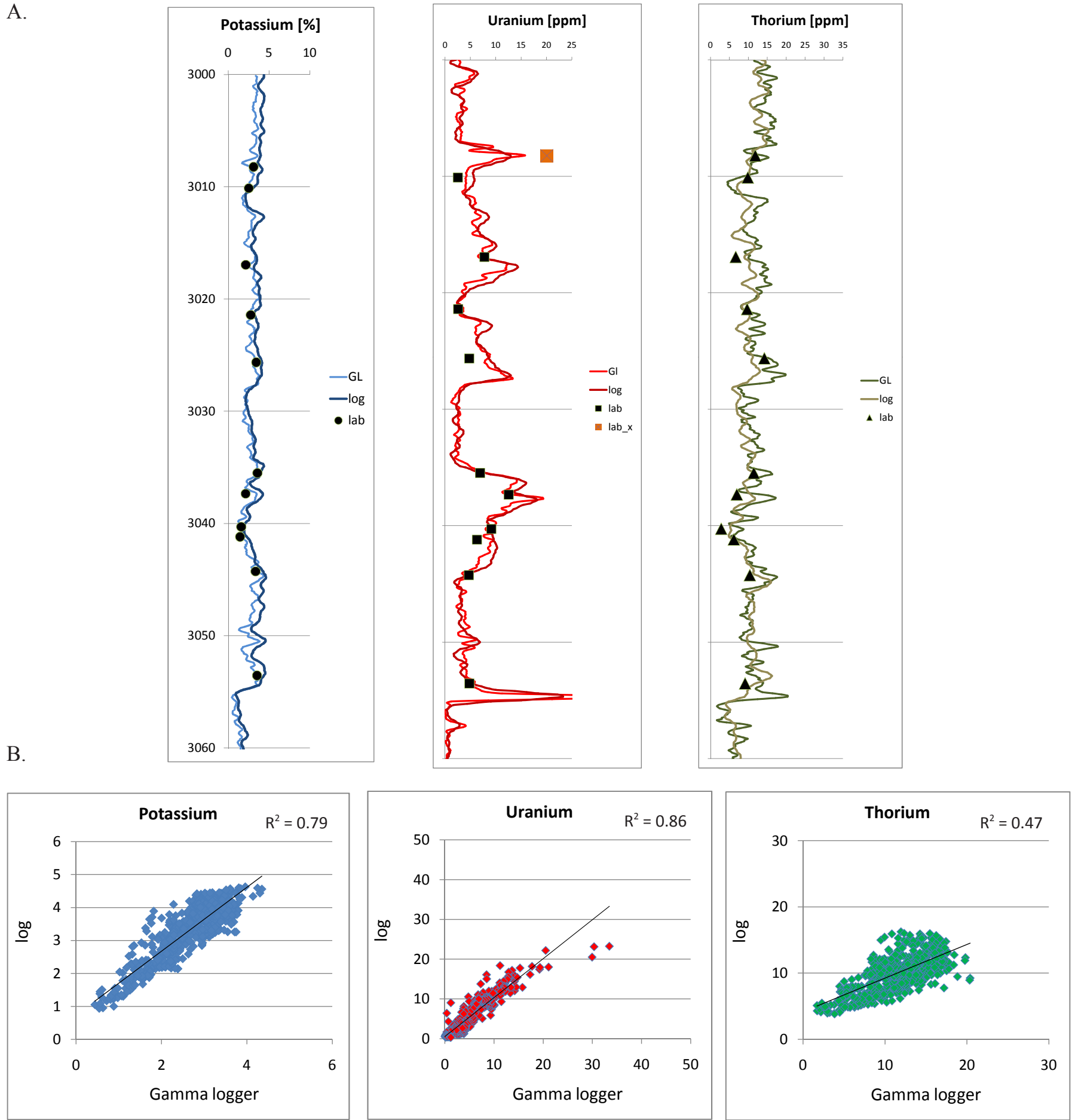

Fig. 5. A - Comparison of laboratory measurements with the results of borehole logging and gamma logger measurements of the core from the T-1: GL - result from the gamma logger; log - result of measurement using a borehole tool;

lab - laboratory measurements. B - Correlation of well log results with the gamma logger data 
fit between the borehole logs and the results of core measurements using the gamma spectroscopy method. Analysing the logs, small differences between the used measurement methods may be noticed. Logs from measurements on the core have been subject to filtration. To this end a Gauss filter has been used, with a filtering interval of $f=5$. Because of filtration the log correlations have substantially improved, but this results in losing some information and reducing the resolution. A misfit of a point from laboratory measurements for uranium in the upper part of the graph, marked in orange, is an example (Fig. 5A). Fig. 5B presents correlations between results from the sonde and from the gamma logger (BGO). For the potassium and uranium concentration values high determination coefficient values were obtained, 0.79 and 0.86 , respectively. A lower value was obtained for the thorium content $(0.47)$. The correlation graph for uranium shows three points of significant overstating of values for the gamma logger. This was caused by averaging the sonde results and understating the actual uranium concentration for thin layers. In the case of thorium statistical fluctuations are higher than for the other elements. This results from the fact that the peak characteristic of thorium, usually having low values, is situated in the high energy part of the registered spectrum [2], for which the detecting crystal has a lower efficiency [1].

The 'GL' log prior to filtration perfectly matches the laboratory measurements point, marked in orange, at a depth of $3008.25 \mathrm{~m}$ [Fig. 6]. The borehole sonde measurement in this range averaged and understated the result, which is best visible on the potassium and uranium log. In the case of potassium the sonde did not register the stratum of a lower concentration of this element, and for uranium the sonde result showed one blurred layer of increased concentration. In fact, two layers of high uranium concentration were recorded on the core, separated by a low radiation layer, $40 \mathrm{~cm}$ thick. Unfortunately, in the case of single thin layers petrophysical tools frequently cannot register the signal due to technical reasons (Fig. 6). With respect to the studies carried out we can state that the measurements on the core give more precise point results for layers of high activity.
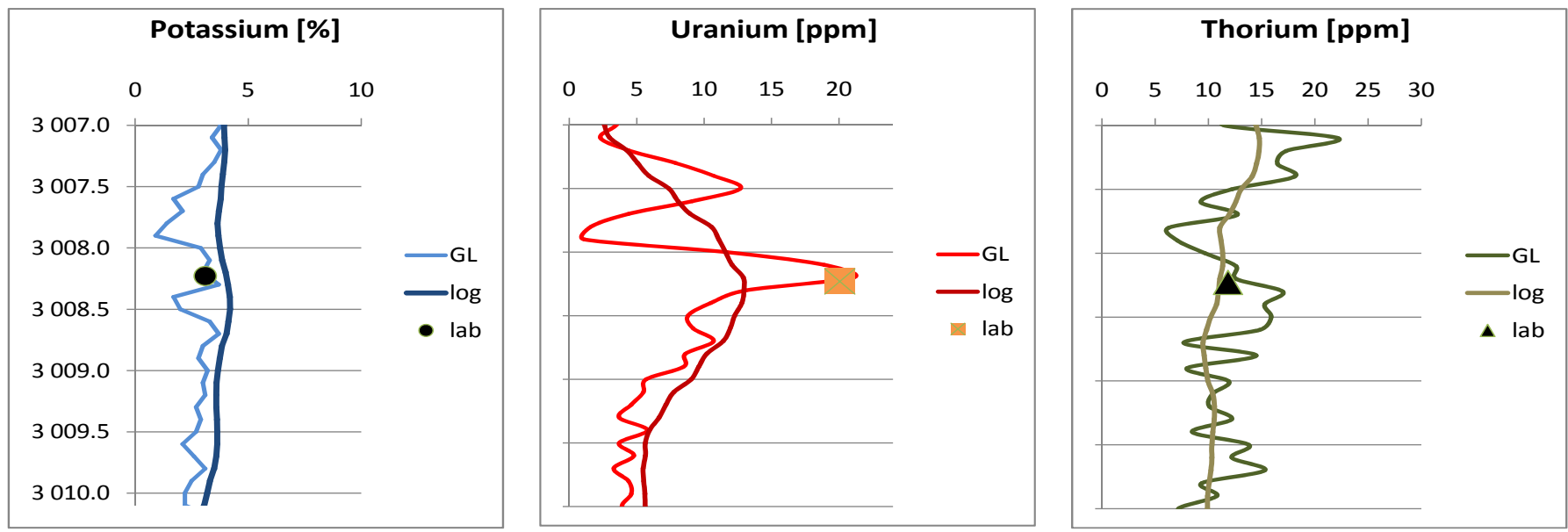

Fig. 6. Comparison of laboratory measurements with results of borehole logging and measurements for the core from the T-1 borehole: GL - result from the gamma logger; log - result of measurement using a sonde; lab - laboratory measurements.

Section from a depth of $3007 \div 3010 \mathrm{~m}$, prior to the log filtration

\section{Summary and Conclusions}

This paper presents a comparison of two instruments used to measure the contents of natural radioactive elements in cores. The work has shown that the instrument equipped with the BGO crystal features a much better precision of performed measurements than the instrument equipped with the NaI crystal. The gamma logger built based on the BGO crystal features a much better sensitivity and efficiency as against spectrometers using the $\mathrm{NaI}$ crystal, assuming the same detector size. Apart from the better parameters of the BGO crystal, the geometric arrangement of the instrument (it was adapted to measure one-metre long core sections) and the application of a lead detector casing, which also covers a fragment of the measured core, could also have contributed to improving the measurements' precision. Further on in the paper an improved process of data acquisition has been presented, and comparative measurements between the gamma logger BGO and laboratory instruments have been described. For the measurement time of 5 minutes very high values of correlation coefficients between measurements were obtained. Unfortunately, this time of measurement is too long to be applied in the field work. Because of that, comparative studies between the aforementioned instruments were performed for 
a time of measurement equal to 60 seconds. In this case lower values of determination coefficient were obtained. However, the result trends for the laboratory spectrometer and the BGO are consistent. In the last comparative study the SPG log from borehole measurements was compared with the BGO device. In this case, for the concentrations of $\mathrm{K}$ and $\mathrm{U}$ elements high values of determination coefficients were obtained. In the case of Th the coefficient was satisfactory.

The carried out studies allow the drawing of the following conclusions:

1. Based on the obtained results and comparisons it is possible to state that shortening the measurement time to 1 minute per point is possible and may be used as a stan- dard method for gamma measurements on shale rock cores with increased radioactivity.

2. Measurements using the presented gamma logger (BGO) enable the obtaining of satisfactory measurement precision and accuracy in a relatively short time of measurement (60 seconds of measurement). Logging by means of the gamma logger enables quick linking of the drilling and well log depth.

3. The device with BGO detector in improved configuration is fit to study active samples, for which the measured signal can be distinguished from the background. For less active rocks this forces work on the minimisation of the surrounding radiation background influence.

Please cite as: Nafta-Gaz 2015, no. 11, pp. 847-855, DOI: 10.18668/NG2015.11.06

Article contributed to the Editors 3.09.2015. Approved for publication 15.10.2015.

The article is the result of research conducted in connection with the project: The methodology for determining sweet spots on the basis of geochemical, petrophysical, geomechanical properties based on the correlation of laboratory test results with geophysical measurements and 3D generating model, co-funded by the National Centre for Research and Development as part of the programme BLUE GAS - POLISH SHALE GAS. Contract No. BG1/MWSSSG/13.

\section{Literature}

[1] BGO Bismuth Germanate Scintillation Material; www.crystals. saint-gobain.com/uploadedFiles/SG-Crystals/Documents/ BGO\%20data\%20sheet.pdf (access on: October 2015).

[2] Blum P., Rabaute A., Gaudon P., James F. Allan: Analysis of natural gamma-ray spectra obtained from sediment cores with the shipboard scintillation detector of the ocean drilling program: example from leg 1561. Shipley T. H., Ogawa Y., Blum P., Bahr J. M. (Eds.): Proceedings of the Ocean Drilling Program. Scientific Results 1997, vol. 156.

[3] Bolesta F., Galazka A.: Profilowanie gamma-przeliczanie jednostek. Nafta-Gaz 2014, no. 8, pp. 493-501.

[4] Ellis D. V.: Well Logging for Earth Scientists. Elsevier NY, 1987.

[5] Hesham A. Yousef, Gehad M. Saleh: Measurement of the Natural Radioactivity in Cataclastic Rock Samples using RS-230 Spectrometer. Greener Journal of Physical Sciences 2013, vol. 3(5), pp. 165-176.

[6] Jarzyna J., Bała M., Zorski T.: Metody geofizyki otworowejpomiary i interpretacja. Wydawnictwa AGH, Kraków 1997.

[7] Kowalska S., Lewandowska A., Buniak A.: Przyczyny powstawania anomalnych wskazan profilowania gamma (sPG) w skalach czerwonego spagowca z rejonu wyniesienia wolsztynskiego. Nafta-Gaz 2010, no. 6, pp. 425-440.
[8] Lüning S., Kolonic S.: Uranium spectral gamma-ray response as a proxy for organic richness in black shales: applicability and limitations. Journal of Petroleum Geology 2003, vol. 26(2), pp. 153-174.

[9] Radulescu I., Rigollet C., Van der Graaf E. R., de Meijer R. J.: Towards sub-centimetre resolution in bore-core logging. Nuclear Instruments and Methods in Physics Research 2007, A 580, pp. 675-678.

[10] Rider M.: The Geological Interpretation of Well Logs. Second Edition, Whittles Publishing 1996, reprinted 2000.

[11] Skupio R.: Accuracy assessment of the determination of radioactive elements concentration on shale cores. Nafta-Gaz 2015, no. 6, pp. 390-399.

[12] Van der Graaf E. R., Rigolleta C., Malekaa P. P., Jonesb D. G.: Testing and assessment of a large BGO detector for beach monitoring of radioactive particles. Nuclear Instruments and Methods in Physics Research 2007, A 575, pp. 507-518.

[13] Vasiliev M. A., Blum P., Chubarian G., Olsen R., Bennight C., Cobine T., Fackler D., Hastedt M., Houpt D., Mateo Z., Vasilieva Y. B.: A new natural gamma radiation measurement system for marine sediment and rock analysis. Journal of Applied Geophysics 2011, vol. 75, pp. 455-463.

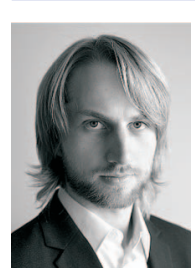

Rafał SKUPIO M.Sc., Eng.

Junior Scientist

Department of Well Logging

Oil and Gas Institute - National Research Institute

ul. Lubicz 25 A

31-503 Kraków

E-mail:rafal.skupio@inig.pl

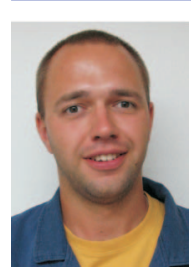

Dr. Eng. Marek DOHNALIK PhD.

Assistant Professor

Head of the Department of Well Logging

Oil and Gas Institute - National Research Institute

ul. Lubicz 25 A

31-503 Kraków

E-mail:dohnalik@inig.pl 